\title{
Fugitive methane emissions from abandoned oil and gas wells in northeastern Oklahoma, USA
}

\author{
Matthew D. ReEDER ${ }^{* 1,2}$, NATAlie PEKNEY ${ }^{1}$, PAtricia \\ SAINT VINCENT ${ }^{1,3}$ \\ ${ }^{1}$ National Energy Technology Laboratory, 626 Cochrans Mill \\ Road, P.O. Box 10940, Pittsburgh, PA 15236-0940, USA \\ ${ }^{2}$ Leidos Research Support Team, 626 Cochrans Mill Road, \\ P.O. Box 10940, Pittsburgh, PA 15236-0940, USA \\ (*correspondence: matthew.reeder@Leidos.com) \\ ${ }^{3}$ Oak Ridge Institute for Science and Education, 626 \\ Cochrans Mill Road, P.O. Box 10940, Pittsburgh, PA \\ 15236-0940, USA
}

Current estimates of the number of abandoned oil and gas wells across the United States range from one to three million wells. These wells can pose an environmental threat either by acting as a conduit for fluid migration to the subsurface or by allowing hydrocarbons to be released into the environment. Given that methane $\left(\mathrm{CH}_{4}\right)$ is colorless and odorless, a well could leak substantial quantities of the gas unnoticed for decades. Compared to carbon dioxide $\left(\mathrm{CO}_{2}\right)$, methane accounts for a significantly smaller percentage of all U.S. greenhouse gas emissions and has a much shorter lifetime in the atmosphere. Methane is, however, far more efficient at trapping heat. Recent studies have provided methane emissions data from abandoned wells in Pennsylvania, Ohio, West Virginia, and Colorado. Despite these efforts, additional data representing a variety of well ages, construction methods, and source formations are needed to better refine the overall methane emissions factor for abandoned wells. To that end, field campaigns were conducted near Oologah Lake, Oklahoma in 2019 and 2020. With a history dating back to the first commercial well in the state in 1897, northeastern Oklahoma has seen numerous rounds of oil and gas exploration and development. A total of 175 methane emissions measurements were made at plugged and unplugged abandoned water injection and oil production wells. According to available public data, the wells that were measured ranged in age from 10 to 100 years old. Methane emissions were detected at 45 of the wells using a hand-held detector (Pergam Mini-G). Of these, methane emissions rates were measurable at 15 wells using a Bacharach Hi-Flow Sampler. The methane flux ranged from 0.1 to $3.3 \mathrm{~L} \mathrm{CH}_{4} / \mathrm{min}$ with an average of 0.58 $\mathrm{L} \mathrm{CH}_{4} / \mathrm{min}$. The data collected from this study will be used to further refine methane emissions factors used in natural gas systems modeling by state and federal agencies. 